\title{
Potential role of mushroom $\beta$-glucans in immunity and inflammation in viral infections and COVID-19
}

\author{
Valentina Konusova, Eugene Vorbeychikov and Mark Shamtsyan*
}

Saint Petersburg State Institute of Technology, Russia

${ }^{*}$ Corresponding author: Mark Shamtsyan, Saint Petersburg State Institute of Technology, Russia. E-mail: mark.shamtsyan@yandex.ru DOI: $10.31665 /$ JFB.2021.16288

Received: September 22, 2021; Revised received \& accepted: November 07, 2021

Citation: Konusova, V., Vorbeychikov, E., and Shamtsyan, M. (2021). Potential role of mushroom $\beta$-glucans in immunity and inflammation in viral infections and COVID-19. J. Food Bioact. 16: 8-18.

\begin{abstract}
According to the concept of trained immunity (TRIM), by stimulating the immune response with one pathogen, one can strengthen it against infection by another. With this understanding, one can take advantage of such immune responses with a stimulant such as $\beta$-glucan, which does not actually cause disease in humans, but has the advantage of generating primed immune cells that will respond to a variety of deadly infections. Mushroom $\beta$-glucans are known to act as training agents that leads to an increase in immune responses when these trained cells are subjected to a secondary stimulus. Understanding whether the TRIM processes are responsible for antiviral responses will undoubtedly provide a deeper understanding of other potential antiviral strategies, as the new SARS-CoV-2 is not the first- or last-time humanity has to deal with viral pandemics. More studies and clinical evidence are necessary for better understanding of the role of $\beta$-glucans in viral infections and COVID-19.
\end{abstract}

Keywords: Beta-glucans; Fungi; Inflamation; Immune modulation; Trained immunity.

\section{Introduction}

The Covid-19 pandemic has posed a whole new set of challenges for humanity. In a short time, it is necessary to develop new strategies to combat this pathology, which has led to serious problems in medicine, the pharmaceutical industry, and the world economy as a whole. Old age as well as metabolic disorders (diabetes, atherosclerosis, obesity), cardiovascular diseases and cancer have been shown to be predictors of a severe course and a fatal outcome of COVID-19. The orientation of the population only towards vaccination is strategically not entirely correct, because without the formation of healthy eating habits, understanding the role of proper and nutritious nutrition for health, providing immunity, it is impossible to cope with this pandemic. Many natural products with potential pharmacological and beneficial effects have shown significant immunomodulatory and general health benefits with minimal or no toxicity.

It has been shown that many structural polysaccharides (glucans, mannans, pectins, arabinogalactans, fucoidans, galactans, hyaluronans, fructans, and xylans) are biopolymers widespread in nature and have immunostimulating activity (Ferreira et al., 2015). Of all the variety of structural polysaccharides, $\beta$-Dglucans are currently the most studied-glucose homopolymers that form a rigid structure of the cell walls of cereals, yeasts, fungi (both pathogenic and edible), as well as some types of bacteria. According to modern views, $\beta$-D-glucans, together with lipopolysaccharides (LPS), muramil dipeptide (MDP), teichoic acids and other archetypal components of microorganisms, are united by the concept of "pathogen-associated molecular patterns" (PAMP). This group of substances has one common property: to activate the innate immune system through interaction with genetically determined receptors specific for each archetype (Leonhardt et al., 2018).

Traditionally, mushrooms are considered a valuable food product containing high amount of proteins rich in essential amino acids. They are also rich in dietary fiber, B vitamins and are sources of ascorbic acid, niacin and biotin.

Along with nutritional value, mushrooms have a number of other beneficial properties. Fungi synthesize a wide variety of biologically active substances, and, thanks to the developed enzymatic 
complexes, are able to consume a wide range of substrates.

Currently, much attention is paid to the medicinal properties of fungi in general and mushrooms and their metabolites. Most of the traditional knowledge about the biologically active properties of mushrooms came to us from East Asia. Mushrooms have traditionally been used in oriental medicine, and their medicinal effects have been known since ancient China. Among them, there are both edible mushrooms, such as Lentinus edodes, Grifola frondosa, Hericium erinaceus, Flammulina velutipes, Pleurotus ostreatus and Tremella mesenterica, and inedible, used only for medicinal purposes (for example, Ganoderma lucidum, Schizophyllum versicolor). Representatives of the genus Ganoderma have the longest history of use as medicines, dating back at least four millennia. In Japan, G. lucidum is known as "reishi" or "manetake", and in China, as "ling zhi" (mushroom of immortality). This mushroom is widely represented in ancient Japanese, Korean and Chinese art and is often used in Chinese royal tapestries (Leonhardt et al., 2018). The healing properties of mushrooms were also known in Europe. The ancient Greek physician Hippocrates, "the father of medicine", reported on the use of mushrooms for the treatment of various chronic diseases. (Willard, 1990).

\section{Immune-stimulating effect of $\beta$-glucans}

At present, the study of the medicinal properties of mushrooms and the creation of preparations based on them are actively developing. As a traditional product of the Orient, medicinal mushrooms are increasingly conquering the western market (Hobbs, 2002). There are more than 14,000 species of higher mushrooms, but only about 3,000 are edible, and about 700 of them are known to have medicinal properties (Sullivan et al., 2006).

Studies have shown that many edible mushrooms are able to strengthen the immune system by affecting cellular activity and promoting the synthesis of chemical compounds that stimulate the immune system, as well as helping to treat diseases and restore immunity destroyed by radiation and chemotherapy (Borchers et al., 2008; Ayeka, 2018; Chen and Seviour, 2007; Vetvicka et al., 2008). This effect is mainly associated with fungal polysaccharides$\beta$-glucans (Reis et al., 2017; Ooi and Liu, 2000). In addition to glucans, mushrooms also contain a number of other compounds that have therapeutic effects. These include polysaccharides, glycoprotein complexes, agaritin, ergosterol, selenium, polyphenols, and terpenoids.

Natural products that can be used to prevent or treat disease have been in great demand throughout human history. The main problem with the characterization of many natural products is that they are a complex mixture of ingredients, each of which can contribute to their biological activity. B-glucans from fungi, yeast and algae are well-known biological response modifiers that act as immunostimulants against infectious diseases and cancer (Borchers et al., 1999; Borchers et al., 2004). Unlike most other natural products, purified $\beta$-glucans retain their bioactivity, which makes it possible to characterize the functioning of $\beta$-glucans at the cellular and molecular level.

B-Glucans are among the main bioactive polysaccharides, which are widely found in plants, fungi, yeasts and bacteria, and have many advantages such as wide sources of raw materials, renewable and good security. The unique structural characteristics of $\beta$-glucans enable them to perform many specific physiological functions. Such as lowering cholesterol, regulating blood sugar and improving immunity. It is a kind of ideal health food, and can be used as food ingredient, with good application value and development prospect. (Brown and Gordon, 2003, Chu et al., 2021).

The actions of these compounds include strengthening the immune system by stimulating lymphocytes, natural killer cells (NKcells) and macrophages, improving cytokine production, inhibiting cancer cell proliferation, stimulating apoptosis, and blocking angiogenesis (Zheng et al., 2018; Gao and Zhou, 2002). More than 50 species of fungi are sources of drugs showing immunomodulatory and antitumor effects in in vitro and in vivo experiments. Among them are lectins, polysaccharides and glycoprotein complexes, such as lentinan, schizophyllan, polysaccharide-K, polysaccharide $\mathrm{P}$, etc. These compounds were obtained, along with the others, from such fungi, as G. lucidum, Ganoderma tsugae, Schizophyllum commune, Sparassis crisberium, Polyporus rhinoceros, Trametes robiniophila, Coriolus versicolor, Lentinus edodes, G. frondosa, and $F$. velutipes (Borchers et al., 2008; Sarangi et al., 2006)

The idea of how $\beta$-D-glucans from edible mushrooms interact with human and animal cells was developed as a result of the study of antifungal immunity. It is known that all living organisms at different stages of development have a defense system against pathogenic fungi. The mechanisms of antifungal defense have evolved evolutionarily from the simplest humoral reactions (for example, clotting of hemolymph in crustaceans) to complex intercellular interactions in the immune system (Medzhitov, 2013).

It should be noted that the analysis of the literature devoted to the study of the pharmacology of $\beta$-glucans of higher fungi is very difficult. First of all, $1 \rightarrow 3,1 \rightarrow 6 \beta$-D-glucans from fungi, the most characterized and possessing a great therapeutic potential, with a similar primary structure, represent an extremely diverse group of biopolymers. It has been shown that the species of the fungus determines the structure of the polymer chain: the presence of side branches, their frequency, weight, etc. Physicochemical characteristics, such as solubility, affinity, are influenced by the extraction methods (Radzki et al., 2016), as a result, $\beta$-D-glucans extracted from fungi and yeast can be in the form of corpuscular insoluble particles, such as zymosan, or structures that form a gel in water.

The sources of glucans are various, including fungi (e.g., mushrooms), yeast and seaweed, as well as barley. Medical glucans (as the ones used by traditional medicine) are principally obtained from edible fungi. By boiling and treating with enzymes from one of the mentioned sources, glucans can be extracted in crude form yielding soluble and insoluble products (Wasser, 2002; Usui et al., 1995; Sawai et al., 2002). There are many forms of soluble $\beta$-glucans evaluated for possible antitumor activity, such as $(1 \rightarrow 3)$ - $\beta$-D-glucan, SSG (Sclerotina sclerotiorum glucan) (Kitamura et al., 1994), Schizophyllan (also sizofran, soniflan) from S. commune (Ohno et al., 1987) and Grifolan from G. frondosa (Fujimoto et al., 1991) and they often exist as a linear triple-helical structure in an aqueous solution (Ishibashi et al., 2001).

Insoluble glucans have been isolated for the first time from $(1 \rightarrow 3)-\beta$-D-glucans, according to the mushroom L. edodes (Blecher and Mackin, 1995). They were also isolated from the cell wall of yeast by using the combination of $\mathrm{NaClO}$ oxidation and dimethylsulfoxide (DMSO) extraction (Chihara et al., 1969). To improve their solubility, derivatization by phosphorylation, either sulfation or amination can be used. However, insoluble $\beta$-glucans were found to possess higher immune stimulating activity than soluble ones and are administered orally. Factors that can greatly infuence the antitumor and immune modulatory activities of the glucans are their structure, molecular weight, degree of branching and conformation (Ohno et al., 1999; Chan et al. 2009; Majtan, 2013). The molecular weight of glucans is dependent upon their source and extraction method (Zhang et al., 1999). 
Table 1. Antiviral action of fungal $\beta$-glucans

\begin{tabular}{|c|c|c|c|}
\hline Origin of $\beta$-glucan & Antiviral effect against & $\begin{array}{l}\text { Host or- } \\
\text { ganism }\end{array}$ & Reference \\
\hline S. cerevisiae & Swine influenza virus & pigs & Jung et al., 2004 \\
\hline S. cerevisiae & Porcine rotavirus & piglets & Chethan et al., 2017 \\
\hline L. edodes & Rotavirus & pigs & Fan et al., 2021 \\
\hline L. edodes, G. Iucidum, A. blasei, I. obliquus & Avian influenza virus & mice & $\begin{array}{l}\text { Vetvicka and } \\
\text { Vetvickova, } 2015\end{array}$ \\
\hline S. cerevisiae & Spring carp viremia & zebrafish & Medina-Gali et al. 2018 \\
\hline P. ostreatus & Influenza & human & Jesenak et al., 2013 \\
\hline P. ostreatus & Herpes Simplex Virus (Type 1) & human & Urbancikova et al., 2020 \\
\hline B. rhodina & $\begin{array}{l}\text { Herpes (HSV-1) and Dengue } \\
\text { (DENV-2) viruses. }\end{array}$ & Cell culture & Lopes et al., 2021 \\
\hline S. cerevisiae & Hepatitis B & mice & Soares et al., 2019 \\
\hline G. lucidum, H. erinaceus, S. commune & Dengue Virus 2 & Cell culture & Ellan et al., 2019 \\
\hline A. brasiliensis, G. Iucidum, L. edodes, T. versicolor & Human immunodeficiency virus (HIV) & human & Adotey et al., 2011 \\
\hline H. fuscum & Echoviruses & Cell culture & Ogbole et al., 2018 \\
\hline A. brasiliensis & Poliovirus type 1 & Cell culture & Faccin et al., 2007 \\
\hline L. squarrosulus & Human Cytomegalovirus & Cell culture & Roy et al., 2020 \\
\hline
\end{tabular}

\section{Induction of trained immunity}

Recent research suggests that innate immune populations may have a form of memory called trained immunity (TRIM), in which innate immune cells undergo metabolic, mitochondrial, and epigenetic reprogramming after exposure to an initial stimulus, resulting in a memory phenotype with enhanced immune responses when undergoes a secondary, heterologous stimulus. It has been shown that induction of TRIM using inducers such as BCG vaccine or $\beta$-glucans can provide protection through altered immune responses against a number of viral infections. Geller and Yan (Geller and Yan, 2020) hypothesized a potential role for $\beta$-glucans in reducing morbidity and mortality due to COVID-19 and put forward several ideas as to how TRIM might actually affect the observed epidemiological events associated with COVID-19. They hypothesized that oral use of $\beta$-glucan for prophylaxis may be an effective way to boost the immune response and alleviate symptoms of COVID-19, although clinical trials are needed to confirm the effectiveness of this treatment and to further investigate the various effects of $\beta$-glucans from various sources.

B-glucans have shown remarkable efficacy against viruses that infect the upper and lower respiratory tract, as well as viruses that cause viral pneumonia. Information on antiviral action of fungal $\beta$-glucans is presented in Table 1 .

The study showed that oral administration of $\beta$-glucan to pigs 3 days prior to swine influenza virus (SIV) infection reduced the severity of microscopic lung lesions caused by SIV and decreased detectable SIV nucleic acid present in the lungs 5, 7 and 10 days after inoculation. Levels of interferon gamma (IFN- $\gamma$ ) and nitric oxide (NO) were significantly increased in bronchoalveolar lavage fluid from pigs treated with $\beta$-glucan (Jung et al., 2004). Increased anti-influenza properties were also observed in mice treated with $\beta$-glucan, where Vetvicka and Vetvickova showed that a 2 -week oral $\beta$-glucan regimen resulted in reduced mortality due to influenza infection (Vetvicka and Vetvickova, 2015). Suppression of phagocytosis is a well-known feature of influenza infections that contributes significantly to the pathogenesis of the disease, and importantly, this study showed that $\beta$-glucan increases the phagocytic capacity of neutrophils (Ishikawa et al., 2016). It has also been shown that $\beta$-glucan increases the production of IL- $1 \beta$, TNF- $\alpha$ and IFN- $\gamma$ in the peripheral blood and enhances the antibody response to influenza infection compared to control. Viral titers have been shown to decrease significantly at the first day after infection, with viral levels particularly decreased in cardiac tissue.

Consistent with these studies, reports indicate that in addition to enhancing cytokine functions, a potential mechanism for increased protection against viral infections of the upper and lower respiratory tract may be associated with an increase in the number, phagocytic capacity, and lysosomal enzymatic activity of alveolar macrophages (AMs) (Sakurai et al. 1992). These changes in AM function and quantity can play a very important role in efficient removal of viruses from the lungs. A study by Medina-Gali et al. (2018) provides support for this study using zebrafish. Fish were injected intraperitoneally with $\beta$-glucan and then challenged with spring carp viremia (SVCV), a deadly virus that causes significant mortality in carp populations. Studies have shown that fish treated with $\beta$-glucan showed a significant increase in survival at 14 days after administration (Ashraf et al., 2016; Medina-Gali et al. 2018; Petit et al., 2019).

Human studies support these findings in animals, where $(1,3)$ (1-6) $\beta$-glucan has been shown to reduce the severity of the physical symptoms of upper respiratory tract infections (URTI) (Dharsono et al., 2019). This study also showed a decrease in systolic and diastolic blood pressure in participants who received $\beta$-glucan. This could have implications for $\beta$-glucan use in COVID-19, as patients with the most severe symptoms requiring intensive care unit (ICU) treatment had significantly higher blood pressure compared to those who did not require ICU care. (Huang et al., 2020). Another study using $\beta$-glucan from the fungus $P$. ostreatus showed a significant reduction in the incidence of lower respiratory tract 


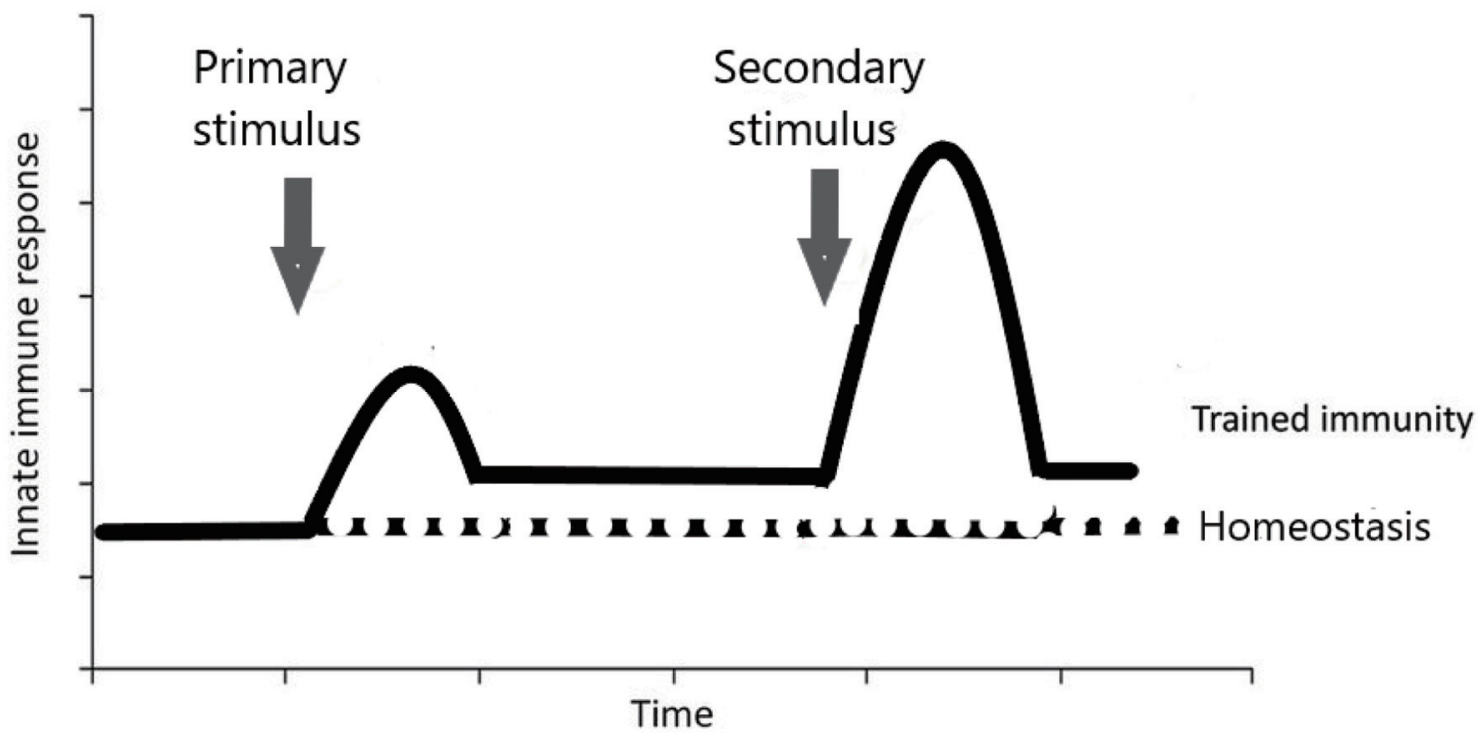

Figure 1. The principle of trained immunity.

infections and the incidence of influenza and flu-like illnesses in children (Jesenak et al., 2013). A study in older adults aged 50-70 who received $\beta$-glucan supplementation for 90 days demonstrated the protective effects of $\beta$-glucan in this high-risk group. In that case, the number of days during which the patient had symptoms of URTI decreased. Increased levels of IFN- $\gamma$ were also found in the blood of the treated individuals (Fuller et al., 2017). Finally, two double-blind, randomized, placebo-controlled trials have shown that orally administered $\beta$-glucan significantly reduces the incidence of cold episodes (by $25 \%$ ) and leads to an easier progression of severe cold episodes (Graubaum et al., 2012; Auinger et al., 2013). While, of course, the symptoms and outcomes of COVID-19 are much more serious than the "common cold," there is evidence that $\beta$-glucan administration can reduce severity and improve outcomes, especially in the most vulnerable populations.

Although $\beta$-glucans themselves induce direct stimulation of immune responses, they are also known to act as a training agent that leads to an increase in immune responses when these trained cells are subjected to a secondary, heterologous stimulus (Figure 1). From an evolutionary point of view, living multicellular organisms have long been battling fungal and bacterial pathogens, and so over time it became logical that organisms lacking adaptive responses developed a way to protect against these recurring infections. This antifungal and bacterial TRIM probably persisted in higher vertebrates, with the result that TRIM was observed after the introduction of $\beta$-glucan or other elements that resemble fungal and bacterial antigens.

Animal studies using $\beta$-glucans support the TRIM paradigm, according to which exposure to $\beta$-glucans followed by secondary infection with Staphylococcus aureus results in protection against the pathogen (Di Luzio and Williams, 1978). TRIM models using various training agents have shown protection against a variety of relevant lethal pathogens such as Streptococcus pneumonia, Toxoplasma gondii, Escherichia coli, and rotavirus (Krahenbuhl et al., 1981: Ribes et al., 2014; Zhang et al., 2014; Netea et al., 2020a). In addition, various examples of BCG and $\beta$-glucan vaccines that provide protection against secondary infections such as Candida albicans in a macrophage-specific manner ultimately led to the idea that the effect on innate immune cells, in particular myeloid cells, of specific training stimuli leads to non-specific immune pro- tection (Bistoni et al., 1988; van’t Wout et al., 1992; Murphy et al., 2012; Legentil et al., 2015; Dos Santos et al., 2019).

\section{Receptors for $\beta$-D-glucans}

At present, there is a well-defined concept of the receptor for dietary $\beta$-D-glucans in mammals. The most important receptors for them today are Dectin-1 and CR3. Some scavenger receptors, lactosylceramide and Toll-like receptors (TLR) 2, 4, 6 are also involved in the recognition of $\beta$-glucans. There are also reports of yet unknown receptors specifically reacting with these polysaccharides (Batbayar et al.,2012; Bose et al., 2013). When administered parenterally, an important role is played by the complement system, activated by $\beta$-glucans in all three ways: classical, alternative and lectin (Swidergall et al., 2018). It is possible to participate in the recognition of $\beta$-glucans from edible mushrooms and other receptors involved in antifungal immunity: CD-5, CD-36, as well as a new pattern recognition receptor (PRR) for $\beta$-glucans belonging to the superfamily of receptor tyrosine kinases-the ephrin receptor type A2 (EphA2) functioning as an epithelial receptor in the oral mucosa (Brown et al., 2007).

The main receptor for $\beta$-D-glucans in mammals is currently considered to be Dectin-1 (CLEC-7A) receptor, which is a member of the large family of type II C-lectin receptors. Dectin-1 is expressed predominantly on myeloid cells: monocytes, macrophages, neutrophils and dendritic cells, natural killer cells (NK), with a high concentration level in organs with a large number of T cells, such as the spleen, thymus and lymph nodes. In humans, it is also localized on B cells, some subpopulations of T cells, and also on eosinophils. However, the functional significance of this expression is currently not fully understood. The presence of Dectin-1 receptors on non-immune cells has also been shown: epithelial cells of the intestine and pulmonary alveoli, fibroblasts and endothelial cells (Drummond and Brown, 2011).

The biological effects caused by $\beta$-glucans via Dectin- 1 are very diverse: phagocytosis, respiratory burst, netosis, autophagy, DC maturation and antigen presentation, activation of inflammasome (NLRP3 and non-canonical caspase-8 inflammasome). In ad- 
dition, by inducing the production of various inflammatory factors: eicosanoids, cytokines and chemokines, Dectin-1 can modulate the immune response induced by other PRRs, directly induce innate immunological memory, and influence the development of CD4 and CD8 cells (Hee et al., 2014). However, the functionality of this receptor has not been fully understood. It has been shown that, in addition to binding polysaccharide structures, Dectin-1 is involved in maintaining the homeostasis of the body, in the regulation of glucose and lipid metabolism, in the formation of antitumor immunity, allergies and autoimmune processes (Du et al., 2019). Human Dectin-1 is a type II transmembrane receptor with a single extracellular carbohydrate recognition domain linked to an intracellular fragment (ITAM-like motif) by a so-called stalk. The presence of the stem makes $\beta$-D-glucans easier to recognize. However, there are 2 isoforms of the Dectin-1 receptor: the full-length A isoform and the stemless isoform $\mathrm{B}$, which are expressed differently on myeloid cells and differentially provide downstream transmission of intracellular signal (Gantner et al., 2003). Sahasrabudhe with coworkers showed that corpuscular forms of $\beta$-glucans react with both variants of the receptor, while soluble forms only with the A isoform (Sahasrabudhe et al. 2016). Intracellular signal transmission from the Dectin-1 receptor, which is necessary for the activation of the transcription factor NF- $\kappa \mathrm{B}$, which implements the program of an innate immune response to $\beta$-D-glucans, is carried out using a variety of downstream pathways. The dominant signaling cascade is the Syk-dependent pathway, which initiates signaling through the Card9/Bcl10/Malt1 channel. In addition, unconventional activation of NF- $\mathrm{KB}$ can proceed through the Raf-1 or noncanonical Syk pathway, as well as through PI3K/Akt signaling (Du et al., 2019). It has also been shown that the Dectin-1 receptor actively interacts with other receptors to enhance the phagocytic response and pro-inflammatory response. First of all, with Tolllike receptors: $2,4,6$. In this case, signal transmission occurs both through the Syk pathway and the traditional TLR Myd88, which leads to enhanced activation of NF- $\mathrm{KB}$ and the production of proinflammatory cytokines (O'Brien et al. 2012). It is possible that there is a cooperation of dectin-1 with other members of the lectin receptor family: SIGNR1 or Dectin-2. It was also established that, in addition to NF- $\mathrm{BB}$, other nuclear transcription factors are also involved in the activation of the immune response mediated by the Dectin-1 receptor: AP-1, NFAT (Du et al., 2019).

The second specific receptor for $\beta$-D-glucans is the CR3 receptor (Mac-1, $\alpha \mathrm{M} \beta 2$ or $\mathrm{CD} 11 \mathrm{~b} / \mathrm{CD} 18)$ and, prior to the discovery of the Dectin-1 receptor, was considered the main receptor for antifungal immunity. CR3 belongs to a large family of $\beta 2$-integrinsstructurally related, heterodimeric, transmembrane receptors consisting of $\alpha$ and $\beta$ subunits (O'Brien et al. 2012). However, CR3 is a unique representative of integrins, because its CD11b subunit contains not one, but two separate binding sites: one for $\beta$-1,3-glucans and the other for the iC3b complement component. Basically, CD11b/CD18 receptors are localized on myeloid cells (neutrophils, monocytes/macrophages, dendritic cells, natural killer cells), which are the main effector cells of the innate immune system. At the same time, the maximum degree of expression of these receptors was noted on neutrophils and natural killer cells (NK), the most reactogenic cells of the early immune response. The main functions of CR3 are the recruitment of neutrophils to the inflammation focus, the initiation of cytotoxic reactions realized through phagocytosis and netosis, the production of cytokines and chemokines. However, to prevent systemic inflammation, the extreme reactogenicity of the effector cells is limited by specific mechanisms of activation signal transmission through CR3. First of all, depending on whether the binding of one receptor site or two (the so-called "double ligation") occurs, the degree of CR ac- tivation is different. As shown, when CR3 interacts on neutrophils with highly purified, soluble, yeast $\beta$-D-glucans, only the polysaccharide site binds, which does not ensure complete activation of the receptor. However, upon meeting with cells opsonized with complement, the second $\mathrm{iC} 3 \mathrm{~b}$ site is ligated, which brings the CR3 receptor into a highly active state, which ensures the functional activity of neutrophils. This phenomenon is the basis for the adjuvant effect of $\beta$-D-glucan preparations when treated with specific antitumor antibodies (Hong et al., 2004). Another feature of the $\mathrm{CD} 11 \mathrm{~b} / \mathrm{CD} 18$ receptor is the ability to be activated by signals coming both from outside to inside (outside-in) and vice versa from inside to outside (inside-out). The inside-out pathway is initiated by signals resulting from the activation of other receptors on the cell, such as TLR or Dectin-1. When the signals are summed, the maximum conformational change in the extracellular domain of the receptor is achieved, which guarantees a high degree of affinity with the ligand. Signal transmission from CR3 has not been fully deciphered to date. However, participation of several signaling pathways has been shown: PI3K, ERK, MAPK (O'Brien et al. 2012).

\section{Mechanistic models of $\beta$-D-glucans interaction with immune system cells}

To understand the pharmacotherapeutic effects caused by $\beta$-Dglucans of higher fungi, it is necessary to have a clear idea of what immune cells and receptors they bind to in the body, what effects they cause. The most appropriate form for understanding these processes is the creation of a mechanistic model that reflects the sequence of processes of interaction of a polysaccharide molecule with cells of the immune system in the body. A well-known difficulty for studying the biological effects caused by polysaccharides isolated from higher fungi is their structural diversity, the lack of well-purified and characterized preparations.

Currently, the Dectin-1 receptor, which stands out among other PRRs by a number of features, is considered a key player in the responses of innate immunity against fungi. First of all, it is both a phagocytic and a signaling receptor, i.e. in antifungal immunity, Dectin-1 mediates both the phagocytic clearance of fungi and the induction of transcription of genes of the innate immune response. The second feature of this lectin receptor is the ability to differentially respond to the physical state of the $\beta$-D-glucan molecule. In the classic work of Goodridge et al., (2011) it was shown that Dectin-1 localized on macrophage cells binds both soluble and corpuscular forms of $\beta$-D-glucan, but glucans in the form of particles are absorbed by actin-mediated phagocytosis, and soluble polysaccharides by clathrin-dependent endocytosis (Goodridge et al., 2011). However, only phagocytosis leads to the generation of reactive oxygen species (ROS) and the activation of NF- $\kappa \mathrm{B}$ in macrophage cells. At the same time, as shown by the authors, for the successful implementation of the phagocytic process, it is necessary to remove the membrane tyrosine phosphatase receptors CD45 and CD148 from the Dectin-1 clustering regions. As a result, the contact of $\beta$-D-glucan with the receptor is formed as a "phagocytic synapse". In contrast, soluble $\beta$-glucans, regardless of their size, are not able to influence the inhibitory activity of membrane tyrosine phosphatases and, thus, to guarantee the transmission of signals from Dectin-1 into the macrophage. The intracellular fate of the physical and chemical variants of $\beta$-D-glucans is also different: the "Dectin-1/corpuscular $\beta$-D-glucan" complex degrades in lysosomes, while the soluble polysaccharide associated with the Dectin-1 receptor migrates into the Golgi apparatus, then are pro- 
cessed, apparently with the help of ROS (Ozment et al. 2012), into small fragments of approximately $25 \mathrm{kDa}$. Further, macrophages move to the bone marrow, spleen and lymph nodes, where there is a slow release of soluble $\beta$-D-glucans and their subsequent absorption in a CR3-dependent way by neutrophils, monocytes, NK cells, as well as tissue macrophages (Hino et al. 2012). It is likely that the activation of innate immunity by corpuscular $\beta$-glucans occurs mainly with the participation of the Dectin-1 receptor, and soluble forms of the polysaccharide are used for this purpose by CR3, using macrophage cells for fragmentation of the polysaccharide and transit to the bone marrow. By the way, in the last decade, the understanding of the role of CR3 receptors in the reactions of innate and adaptive immunity (Sekheri et al. 2021) has been significantly expanded, and their regulatory effect on the polarization of myeloid cells in inflammation and tumor growth has been shown ( Mezu-Ndubuisi and Maheshwari, 2021). Interestingly, low-molecular-weight CR3 agonists, such as leukaderin 1, bind to the CD11b subunit of the receptor and exert anti-inflammatory and antitumor effects by the same mechanisms as $\beta$-D-glucans (Schmid et al., 2018).

It should be noted that the concept of the pharmacokinetics of $\beta$-D-glucans is based only on data obtained from animal experiments. Therefore, there are still many questions related to the traffic of $\beta$-D-glucans in the human body. Studies in rodents show that the processing of immobilized glucans in cells lasts 3-5 days after ingestion, the fragments are released from the 5-10th day, stopping completely after 14-21 days. The conversion process for soluble $\beta$-D-glucans is shorter, but precise data are not available (Rice et al., 2005). It is likely that the slow and prolonged process of processing immobilized glucans causes a longer immune response compared to soluble forms of mushroom polysaccharides. It should be noted that the method of administration of soluble $\beta$-D-glucans in general does not affect their pharmacotherapeutic efficacy. If glucan delivered intravenously binds directly in the bloodstream to CR3 receptors on circulating granulocytes, then orally administered $\beta$-D-glucan passes an intermediate stage in the gastrointestinal tract, through the absorption of Dectin-1 receptors on macrophages localized in Peyer's patches, and partially on intestinal epithelial cells and then, after fragmentation of the polysaccharide, is provided to granulocyte cells in the bone marrow. However, it cannot be ruled out that parenteral administration of $\beta$-glucan drugs will be somewhat more effective, because this route of drug delivery assumes the participation of the complement system. Apparently, today, despite the large experimental and clinical experience of using $\beta$-D-glucans obtained from higher fungi, we still do not have a complete understanding of the mechanism of their action.

In the scientific and popular literature, $\beta$-D-glucans isolated from fungi are characterized as the most powerful stimulants of the immune system (Vetvicka et al., 2019). Experiments on cells have shown that fungal glucans activate a large number of genes encoding both pro-inflammatory cytokines, such as TNF, IL-6 and IL-23, and others, as well as regulatory ones: IL-2 and IL10 (Goodridge et al., 2009). In this case, the spectrum of induced cytokines differs from the cytokines stimulated through TLR receptors, which most likely reflects the specificity of the antifungal response. However, evolutionarily, the Dectin-1 response is closely associated with Toll receptors; therefore, in some cases, the antifungal immune response is enhanced by the MyD88 TLRcoupled signaling pathway. The peculiarities of the immune response to pathogenic fungi determine other distinctive features of the immunostimulating action of $\beta$-D-glucan drugs: assistance in the maturation and activation of dendritic cells, which provide the relationship between innate and acquired immunity; the ability to direct the formation of adaptive immunity predominantly in the Th1 and Th17 types, induce strong production of reactive oxygen species (ROS), trigger the production of NLRP3 inflammasome, which is necessary for converting the inactive form of the cytokine pro-IL- $1 \beta$ into functionally active IL- $1 \beta$, which is one of the most important for antifungal immunity, and initiate cytotoxic $\mathrm{T}$ cells (Kankkunen et al., 2010). The specificity of the immune response to pathogenic fungi, which has a predominantly Th1 profile, explains the high efficiency of $\beta$-D-glucans used for the prevention of cancer and seasonal colds of a viral nature (Tanaka et al., 2016). It is possible that for these purposes it is more expedient to use corpuscular forms of $\beta$-D-glucans, which provide a longer stimulating effect.

Particular interest in $\beta$-D-glucan preparations has arisen in the last decade in connection with the concept of "trained immunity", which has radically changed the concept of the formation of defense mechanisms of the immune system. It has been shown that the preliminary administration of the two most potent immunity inducers to animals, BCG and $\beta$-D-glucans, protects them from subsequent infection (van der Meer et al., 2015). The phenomenon was explained by the formation of immunological memory of innate immunity and was called "trained immunity". Unlike classical immunological memory, which stores information about all contacts with infectious agents, practically throughout life, in the genome of specialized T and B cells, the so-called "memory cells", the formation of "trained immunity" does not affect the DNA sequence. As shown by numerous studies, during the primary interaction of monocyte-macrophage cells with PAMPs (pathogen-associated molecular patterns), epigenetic transformation occurs in their genome, accompanied by the modification of histones and DNA methylation. As a result, the chromatin structure becomes looser, and upon repeated contact with the pathogen, the availability of the transcription factor NF-kB for intracellular signals transmitted from the innate receptor system becomes higher, which leads to an increase in the production of pro-inflammatory cytokines (IL-1, IL-6, TNF, IL-8, etc.) and ROS. At the same time, changes in cellular metabolism occur. If for resting cells the usual type of respiration is oxidative phosphorylation, then "trained immunity" is characterized by aerobic glycolysis. This type of metabolism is required by myeloid cells for rapid cell proliferation. All these processes optimize the innate immune response, increasing the body's resistance to infection, both bacteria and viruses. However, $\beta$-glucans not only induce trained immunity in mature monocytes and macrophages, but also alter the functional program of hematopoietic progenitors in the bone marrow, which probably explains the long-term identification of trained myeloid cells in the bloodstream (Mitroulis et al., 2018). The identification of the molecular mechanisms involved in the training of myelocytes by $\beta$-D-glucans revealed the involvement of the PI3K/AKT/mTOR signaling pathway, which determines cell metabolism towards aerobic glycolysis (Cheng et al., 2014) and the proinflammatory cytokine IL-1 $\beta$, as a key mediator of reprogramming at the precursor level. bone marrow (Saeed et al., 2014).

Today, cells of the monocytic lineage (monocytes/macrophages) are considered the main targets of trained immunity (Moerings et al., 2021). However, it was noted that the most studied agonists of trained immunity (BCG, $\beta$-D-glucans) exhibit antitumor activity. For example, trained immunity induced by pretreating mice with $\beta$-glucans resulted in decreased tumor growth. The studies carried out by Kalafati et al. (2020) showed that the antitumor effects of the trained immunity induced by the $\beta$-glucan from Trametes versicolor were mainly associated with the transcriptomic and epigenetic rearrangement of granulopoietic progenitors in the bone marrow, as a result of which neutrophil cells acquired an antitumor 
phenotype (Kalafati et al., 2020). These studies demonstrated that granulocytes are also an integral part of trained human immunity, just like monocytes/macrophages. It should be noted that, in general, experiments on the study of trained immunity were carried out with corpuscular polysaccharides; as a result, it was concluded that only $\beta$-D-glucans in this physicochemical form cause epigenetic modulation of the genome. However, studies demonstrating the important role of IL- $1 \beta$ as a key mediator of reprogramming at the bone marrow progenitor level suggests that soluble glucans, which are good inducers of this pro-inflammatory cytokine, may also train immunity. It can also be assumed that corpuscular $\beta$-Dglucans reprogram monocytes/macrophages with the participation of the Dectin-1 receptor, and CR3 mediates the learning of cells of the granulocytic series. Unfortunately, there is little research into the training properties of mushroom $\beta$-glucans. Until now, the time parameters of the epigenetic effect of glucans have not been determined. According to various sources, the effect of the trained immunity caused by fungal glucans lasts from 7 days to one month. In addition, the schemes and duration of drug administration are not clear. Therefore, clinical trials are now needed to determine the safety profile and efficacy of $\beta$-glucans for the prevention of infections.

However, despite the lack of information about clinical trials, at the very beginning of the Covid-19 epidemic, several reviews appeared simultaneously, suggesting mushroom polysaccharides as inducers of innate immunity reprogramming (Kalafati et al., 2020; Netea et al. 2020b). It is emphasized that $\beta$-glucans are unique biomolecules that not only cause epigenetic transformation of myeloid cells, but are also able to quickly and vigorously activate Th1-type adaptive responses, which are so important for an effective response to viral infection. There is also evidence that $\beta$-glucan-treated and trained dendritic cells are more effective in supporting B-cell responses and generating neutralizing antibodies, which additionally helps to translate an early innate immune response towards a long-term hyperspecific adaptive response (Geller and Yan, 2020).

B-D-glucans from mushrooms are considered the most powerful immune stimulants of natural origin, as confirmed by numerous studies, both in animals and humans (Chan et al., 2009). However, they should be more correctly classified as "modifiers of biological reactions", which can be especially clearly understood when analyzing their anti-inflammatory action. Studies performed with $\beta$-glucans on isolated blood cells or special, so-called transporter cell lines (RAW 264.7), with myeloid cell differentiation and expression of Dectin-1 receptors, demonstrate a pronounced activation of NF- $\mathrm{kB}$ and the production of pro-inflammatory cytokines: TNF- $\alpha$, IL-1 $\beta$ and IL-6 (Kim et al., 2011). However, when cells are treated with inductors that modulate inflammation: LPS, phorbol esters, etc., $\beta$-glucans have the opposite effect (Baskaran et al., 2017). The same effects were obtained in animal experiments using fungal $\beta$-glucans. Liang J. E. et al, showed that pre-administration of $\beta$-glucans to rats with polymicrobial sepsis resulted in a decrease in the level of pro-inflammatory cytokines TNF- $\alpha$ and IL-6, while increasing the anti-inflammatory cytokine IL-10 (Liang et al., 1998). At the same time, the production of antioxidant enzymes, which reduce the phenomena of oxidative stress, increased. A number of studies performed on the model of sepsis caused by ischemia-reperfusion of the abdominal aorta in rats, accompanied by lung damage, have demonstrated that $\beta$-glucans reduce the systemic inflammatory response by reducing oxidative stress and lipid peroxidation in the lung tissue, reducing the permeability of pulmonary microvessels and suppression of the processes of infiltration of leukocytes into the lungs (Sandvik et al., 2007; Gülmen et al., 2010). In the literature, there are a number of reports on the use of fungal polysaccharides in humans for the prevention of septic complications after severe abdominal surgery and multiple injuries. Thus, Dellinger et al. (1999) showed that the administration of yeast PGG glucan to patients 12-24 hours before surgery reduced mortality (in the control group- $30 \%$, among patients-4.8\%) and the number of infectious complications, reduced the need for intravenous antibiotics, and also reduced days of intensive care (Dellinger et al., 1999). Unfortunately, the large variability in the structure of $\beta$-D-glucans, the poor characterization of finished drugs, and the lack of a complete understanding of the mechanisms of their action significantly complicate the conduct of such clinical studies.

\section{Future research directions}

Indeed, the mechanisms by which $\beta$-D-glucans suppress inflammation have not yet been elucidated. Several factors can be identified that explain their anti-inflammatory effect. Thus, in early experimental studies, it was shown that the inhibition of inflammation by $\beta$-D-glucan in rats with sepsis was caused by a switch of intracellular signaling to the Akt/P13K anti-inflammatory pathway (Kaneda et al., 2016). Recent studies have established that this pathway, along with other modulation signaling molecules, including NF-kB, Maps, AP-1, STAT1, STAT6, IRF-4, IRF-5, PPARy, KLF4, controls the biology of macrophages. Macrophage cells are essential components of the inflammatory response, participating in antigen presentation, phagocytosis, immunomodulation and tissue repair (Sica and Mantovani, 2012). Depending on their environment, they can be polarized, both classically activated-M1 with pro-inflammatory properties, and alternatively activated-M2 with anti-inflammatory properties (Municio et al., 2013). Therefore, modulation of their phenotype can determine the initiation, development and resolution of inflammatory processes. Apparently, the effect of natural compounds, which include $\beta$-D-glucans, on inflammation processes may be associated with their regulatory effect on macrophage biology, mediated through evolutionarily ancient signaling pathways. Another possible mechanism may be associated with inflammasomes, multiprotein inflammatory complexes that regulate inflammation through the production of IL-1 $\beta$ and IL-18. Previously, it was shown that $\beta$-D-glucans in intact myeloid cells induce the production of IL-1, both through direct cell activation and through the formation of an inflammasome (Rice et al., 2005). However, pretreatment of cells with $\beta$-glucan decreased macrophage secretion of mature IL- $1 \beta$ in response to stimuli that activate NLRP3 (Camilli et al., 2020). Analyzing the mechanisms of the anti-inflammatory action of $\beta$-D-glucans, it can be concluded that most likely all these processes are also associated with epigenetic training of innate immune cells.

Among the problems that have arisen in connection with the Covid 19 pandemic, one of the most serious is the state of health of the world's population. As the nosological analysis of diseases accompanying especially severe clinical forms and death from covid infection shows, these are, first of all, diseases united by the concept of "metabolic syndrome", including such conditions as: abdominal obesity, atherosclerosis, hypertension, type 2 diabetes. In addition, old age, which itself is a predictor of the most severe course of this infection, appears to be a factor that increases the risks for individuals with metabolic dysfunctions (Du et al., 2020). According to modern concepts, aging and diseases associated with metabolic disorders are united by such a pathological process as "chronic low-grade inflammation" (Minihane et al., 2015). The trigger mechanism for the development of this condition is, first 
of all, changes in the intestinal microbiota caused by age and dietary disorders, leading to translocation through the intestinal wall of bacterial lipopolysaccharides (LPS)-powerful stimulants of inflammation (Belkaid and Hand, 2014). Long-term circulation of LPS in the bloodstream gradually leads to a dysregulation of glucose and lipid metabolism in adipose tissue, skeletal muscles and liver; multiorgan cardiometabolic dysfunction; decrease in the functionality of the adaptive and innate immune systems. These changes in the immune system, called immunosenscence, are characterized by a decrease in naive CD $4+$ and $\mathrm{CD} 8+\mathrm{T}$ cells, an imbalance in the qualitative and quantitative composition of $\mathrm{T}$ cells, and a violation of the functional activity of dendritic cells (Pawelec, 2018). Macrophage cells, which are in a state of constant activation, contain a large number of inflammasomes, which instantly trigger systemic inflammation upon infection (Vandanmagsar et al., 2011). It is clear that all these pathological changes lead to the failure of the immune system, which is unable to form a defense against infection. In all likelihood, right now, during a pandemic, it is necessary to seriously pay attention to the formation of correct dietary habits in the population, to explain that not only vaccination is important, but also a healthy diet. The prophylactic use of $\beta$-D-glucans can be an excellent practice to slow down the processes of "chronic low-grade inflammation" and reduce the risk of developing a severe course of Covid-19.

Rational correction of the functional activity of the immune system is a necessary measure for many diseases and pathological conditions of the body. The most expedient and pathogenetically justified is the use of agents that activate the primary link of immunity-macrophages. Substances of various chemical structures and origins, such as endotoxins, viruses, bacteria, can act as activators of macrophages. However, their use is far from always highly effective and safe in relation to the complications of the therapy, and compounds of the beta-1,3/1,6-glucan and beta-1,3 (D)-glucan class, on the contrary, are safe, including in toxicologically (class generally recognized as safe (GRAS) according to the classification of the Food and Drug Administration (FDA), USA, 2001) and can be used both enterally and parenterally. This pharmacokinetic feature of $\beta$-glucans determines their widespread use in medical practice.

\section{Conclusion}

Preliminary evidence suggests that innate immune responses in COVID-19 are necessary to create a successful immune response, and when this fails, hyperinflammation occurs. B-glucans have been shown to have a number of antiviral properties, and it is suggested that its role as an inducer of TRIM may promote immune responses against SARS-CoV-2 and may help prevent severe clinical manifestations. Pending the development of an effective vaccine, it will be necessary to focus on prophylactic and therapeutic options that can be safely and quickly implemented to enhance immune responses.

It has been suggested that oral prophylactic $\beta$-glucans may be an effective, inexpensive, and safe way to support this immune response, however, clinical studies and trials are needed to confirm the safety and efficacy of this treatment, and to determine which sources and specific doses of $\beta$-glucan may be most effective in this context. In addition, although oral $\beta$-glucan would be the safest route of administration and indeed exhibit important physiological effects, the method of administration of $\beta$-glucan also requires further study. As such, research on this topic is important, and the design of clinical trials is needed to answer these questions and to evaluate this potentially important treatment. Finally, in order to understand the antiviral mechanisms of $\beta$-glucan, it is important to distinguish between general immunostimulatory effects and those induced by TRIM induction. This is especially important because, if a TRIM-mediated mechanism is involved, the use of $\beta$-glucans as a prophylactic agent may be an indicated clinical course, however, if it is associated with direct immunostimulatory effects, $\beta$-glucan can be used as a therapeutic agent.

Understanding whether the TRIM processes are responsible for antiviral responses will undoubtedly provide a deeper understanding of other potential antiviral strategies, as the new SARS-CoV-2 is not the first- or last-time humanity has to deal with viral pandemics.

Prophylactic use of oral $\beta$-glucan may be an effective, inexpensive and safe way to support the immune response against SARS-Cov-2 and other viruses and help to prevent severe clinical manifestations, but clinical studies and trials are needed to confirm safety and efficacy of this treatment.

\section{References}

Adotey, G., Quarcoo, A., Holliday, J.C., Fofie, S., and Saaka, B. (2011). Effect of immunomodulating and antiviral agent of medicinal mushrooms (immune assist 24/7) on CD4+ T-lymphocyte counts of HIV-infected patients. Int. J. Med. Mushrooms. 13(2): 109-113.

Ashraf, U., Lu, Y., Lin, L., Yuan, J., Wang, M., and Liu, X. (2016). Spring viraemia of carp virus: recent advances. J. Gen. Virol. 97: 1037-1051.

Auinger, A., Riede, L., Bothe, G., Busch, R., and Gruenwald, J. (2013). Yeast $(1,3)-(1,6)-\beta$-glucan helps to maintain the body's defence against pathogens: a double-blind, randomized, placebo-controlled, multicentric study in healthy subjects. Eur. J. Nutr. 52: 1913-1918.

Ayeka, P.A. (2018). Potential of Mushroom Compounds as Immunomodulators in Cancer Immunotherapy: A Review. Evid. Based Complement Alternat. Med. 2018: 7271509.

Baskaran, A., Chua, K.H., Sabaratnam, V., Ram, M.R., and Kuppusamy, U.R. (2017). Pleurotus giganteus (Berk. Karun \& Hyde), the giant oyster mushroom inhibits NO production in LPS/H2O2 stimulated RAW 264.7 cells via STAT 3 and COX-2 pathways. BMC Complement Altern Med. 17: 40.

Batbayar, S., Lee, D.H., and Kim, H.W. (2012). Immunomodulation of fungal $\beta$-Glucan in host defense signaling by Dectin-1. Biomol. Ther. 20 433-445.

Belkaid, Y., and Hand, T.W. (2014). Role of the microbiota in immunity and inflammation. Cell 157: 121-141.

Bistoni, F., Verducci, G., Perito, S., Vecchiarelli, A., Puccetti, P., Marconi, P., and Cassone, A. (1988). Immunomodulation by a low-virulence, agerminative variant of Candida albicans. Further evidence for macrophage activation as one of the effector mechanisms of nonspecific anti-infectious protection. J. Med. Vet. Mycol. 26: 285-299.

Blecher, P., and Mackin, W. (1995). Betafectin PGG-glucan: a novel carbohydrate immunodulator with anti-infective properties. J. Biotechnol. Healthcare 2: 207-222.

Borchers, A.T., Keen, C.L., and Gershwin, M.E. (2004). Mushrooms, tumors, and immunity: an update. Exp. Biol. Med. 229(5): 393-406.

Borchers, A.T., Krishnamurthy, A., Keen, C.L., Meyers, F.J., and Gershwin, M.E. (2008). The immunobiology of mushrooms. Exp. Biol. Med. 233(3): 259-276.

Borchers, A.T., Stern, J.S., Hackman, R.M., Keen, C.L., and Gershwin, M.E. (1999). Mushrooms, tumors, and immunity. Proc. Soc. Exp. Biol. Med. 221: 281-293.

Bose, N., Chan, A.S.H., Guerrero, F., Maristany, C.M., Qiu, X., Walsh, R.M., Ertelt, K.E., Bykowski Jonas, A., Gorden, K.B., Dudney, C.M., Wurst, L.R., Danielson, M.E., Elmasry, N., Magee, A.S., Patchen, M.L., and Vasilakos, J.P. (2013). Binding of Soluble Yeast $\beta$-Glucan to Human Neutrophils and Monocytes is Complement-Dependent. Front. Immunol. 4: 230.

Brown, G.D., and Gordon, S. (2003). Fungal $\beta$-glucans and mammalian im- 
munity. Immunity 19(3): 311-315.

Brown, J., O'Callaghan, C.A., Marshall, A.S., Gilbert, R.J.C., Siebold, C., Gordon, S., Brown, G.D., and Jones, E.Y. (2007). Structure of the fungal beta- glucan-binding immune receptor dectin-1: implications for function. Protein Sci. 16(6): 1042-1052.

Camilli, G., Bohm, M., Piffer, A.C., Lavenir, R., Williams, D.L., Neven, B., Grateau, G., Georgin-Lavialle, S., and Quintin, J. (2020). B-Glucaninduced reprogramming of human macrophages inhibits NLRP3 inflammasome activation in cryopyrinopathies. J. Clin. Invest. 130(9): 4561-4573.

Chan, G.C., Chan, W.K., and Sze, D.M. (2009). The effects of $\beta$-glucan on human immune and cancer cells. J. Hematol. Oncol. 2: 25

Chen, J., and Seviour, R. (2007). Medicinal importance of fungal $\beta-(1 \rightarrow 3)$, $(1 \rightarrow 6)$-glucans. Mycol. Res. 111(6): 635-652.

Cheng, S.C., Quintin, J., Cramer, R.A., Shepardson, K.M., Saeed, S., Kumar, V., Giamarellos-Bourboulis, E.J., Martens, J.H.A., Rao, N.A., Aghajanirefah, A., Manjeri, G.R., Li, Y., Ifrim, D.C., Arts, R.J.W., van der Veer, B.M.J.W., Deen, P.M.T., Logie, C., O'Neill, L.A., Willems, P., van de Veerdonk, F.L., van der Meer, J.W.M., Ng, A., Joosten, L.A.B., Wijmenga, C., Stunnenberg, H.G., Xavier, R.J., and Netea, M.G. (2014). mTOR- and HIF-1alpha-mediated aerobic glycolysis as metabolic basis for trained immunity. Science 345(6204): 1250684.

Chethan, G.E., Garkhal, J., Sircar, S., Malik, Y.P.S., Mukherjee, R., Sahoo, N.R., Agarwal, R.K., and De, U.K. (2017). Immunomodulatory potential of $\beta$-glucan as supportive treatment in porcine rotavirus enteritis. Vet. Immunol. Immunopathol. 191: 36-43.

Chihara, G., Maeda, Y., Hamuro, J., Sasaki, T., and Fukuoka, F. (1969). Inhibition of Mouse Sarcoma 180 by Polysaccharides from Lentinus edodes (Berk.) Sing. Nature 222: 687-688.

Chu, H.S.S., Boyer, R., Williams, R., and O'Keefe, S.F. (2021). Preliminary evaluation of inhibitory activity of medicinal mushroom extracts against pathogenic bacteria and spoilage yeasts. LWT-Food Science and Technology 145: 111200.

Dellinger, E.P., Babineau, T.J., Bleicher, P., Kaiser, A.B., Seibert, G.B., Postier, R.G., Vogel, S.B., Norman, J., Kaufman, D., Galandiuk, S., and Condon, R.E. (1999). Effect of PGG-glucan on the Rate of Serious Postoperative Infection or Death Observed After High-Risk Gastrointestinal Operations. Arch. Surg. 134: 977-983.

Dharsono, T., Rudnicka, K., Wilhelm, M., and Schoen, C. (2019). Effects of yeast $(1,3)-(1,6)-\beta$-glucan on severity of upper respiratory tract infections: a double-blind, randomized, placebo-controlled study in healthy subjects. J. Am. Coll. Nutr. 38: 40-50.

Di Luzio, N.R., and Williams, D.L. (1978). Protective effect of glucan against systemic Staphylococcus aureus septicemia in normal and leukemic mice. Infect. Immun. 20: 804-10.

Dos Santos, J.C., Barroso de Figueiredo, A.M., Teodoro Silva, M.V., Cirovic, B., de Bree, L.C.J., Damen, M., Moorlag, S.J.C.F.M., Gomes, R.S., Helsen, M.M., Oosting, M., Keating, S.T., Schlitzer, A., Netea, M.G., RibeiroDias, F., and Joosten, L.A.B. (2019). $\beta$-Glucan-induced trained immunity protects against leishmania braziliensis infection: a crucial role for IL-32. Cell. Rep. 28: 2659-2672.e6.

Drummond, R.A., and Brown, G.D. (2011). The role of dectin-1 in the host defense against fungal infections. Curr. Opin. Microbiol. 14: 392-399.

Du, B., Meenu, M., Liu, H., and Xu, B. (2019). A Concise Review on the Molecular Structure and Function Relationship of $\beta$-Glucan. Int. J. Mol. Sci. 20(16): 4032.

Du, R.H., Liang, L.R., Yang, C.Q., Wang, W., Cao, T.Z., Li, M., Guo, G.Y., Du, J., Zheng, C.L., Zhu, Q., Hu, M., Li, X.Y., Peng, P., and Shi, H.Z. (2020). Predictors of mortality for patients with COVID-19 pneumonia caused by SARS-CoV-2: a prospective cohort study. Eur. Respir. J. 55: e2000524.

Ellan, K., Thayan, R., Raman, J., Hidari, K.I.P.J., Ismail, N., and Sabaratnam, V. (2019). Anti-viral activity of culinary and medicinal mushroom extracts against dengue virus serotype 2: an in-vitro study. BMC Complement Altern. Med. 19(1): 260.

Faccin, L.C., Benati, F., Rincão, V.P., Mantovani, M.S., Soares, S.A., Gonzaga, M.L., Nozawa, C., and Carvalho Linhares, R.E. (2007). Antiviral activity of aqueous and ethanol extracts and of an isolated polysaccharide from Agaricus brasiliensis against poliovirus type 1. Lett. Appl. Microbiol. 45(1): 24-28.

Fan, X., Hu, H., Chen, D., Yu, B., He, J., Yu, J., Luo, J., Eckhardt, E., Luo, Y., Wang, J., Yan, H., and Mao, X. (2021). Lentinan administration allevi- ates diarrhea of rotavirus-infected weaned pigs via regulating intestinal immunity. J. Animal. Sci. Biotechnol. 12: 43.

Ferreira, S.S., Passos, C.P., Madureira, P., Vilanova, M., and Coimbra, M.A. (2015). Structure-function relationships of immunostimulatory polysaccharides: A review. Carbohydr Polym. 132(5): 378-96.

Fujimoto, S., Furue, H., Kimura, T., Kondo, T., Orita, K., Taguchi, T., Yoshida, K., and Ogawa, N. (1991). Clinical outcome of postoperative adjuvant immunochemotherapy with sizofran for patients with resectable gastric cancer: a randomised controlled study. Eur. J. Cancer 27: 11141118.

Fuller, R., Moore, M.V., Lewith, G., Stuart, B.L., Ormiston, R.V., Fisk, H.L., Noakes, P.S., and Calder, P.C. (2017). Yeast-derived beta-1,3/1,6 glucan, upper respiratory tract infection and innate immunity in older adults. Nutrition 39-40: 30-35.

Gantner, B.N., Simmons, R.M., Canavera, S.J., Akira, S., and Underhill, D.M. (2003). Collaborative induction of inflammatory responses by dectin-1 and Toll-like receptor 2. J. Exp. Med. 197: 1107-1117.

Gao, Y., and Zhou, S. (2002). The Immunomodulating Effects of Ganoderma lucidum (Curt.: Fr.) P. Karst. (Ling Zhi, Reishi Mushroom) (Aphyllophoromycetideae). Int. J. Med. Mushrooms. 4(1): 1-11.

Geller, A., and Yan, J. (2020). Could the Induction of Trained Immunity by $\beta$-Glucan Serve as a Defense Against COVID-19? Front. Immunol. 11: 1782.

Goodridge, H.S., Reyes, C.N., Becker, C.A., Katsumoto, T.R., Ma, J., Wolf, A.J. Bose, N., Chan, A.S.H., Magee, A.S., Danielson, M.E., Weiss, A., Vasilakos, J.P., and Underhill, D.M. (2011). Activation of the innate immune receptor Dectin-1 upon formation of a "phagocytic synapse". Nature 472(7344): 471-475.

Goodridge, H.S., Wolf, A.J., and Underhill, D.M. (2009). $\beta$-glucan Recognition by the Innate Immune System. Immunol. Rev. 230(1): 38-50.

Graubaum, H.J., Busch, R., Stier, H., and Gruenwald, J. (2012). A doubleblind, randomized, placebo-controlled nutritional study using an in soluble yeast $\beta$-glucan to improve the immune defense system. Food Nutr. Sci. 3: 738-746.

Gülmen, Ş., Kiris, I., Kocyigit, A., Dogus, D.K., Ceylan, B.G., and Meteoglu, I. (2010). $\beta$-Glucan Protects against Lung Injury Induced by Abdominal Aortic Ischemia-Reperfusion in Rats. J. Surg. Res. 164(2): e325-e332.

Hee, D., Ha, L., and Kim, W. (2014). Innate Immunity Induced by Fungal $\beta$-Glucans via Dectin-1 Signaling Pathway. Int. J. Med. Mushr. 16(1): $1-16$.

Hino, S., Kito, A., Yokoshima, R., Sugino, R., Oshima, K., Morita, T., Okajima, T., Nadano, D., Uchida, K., and Matsuda, T. (2012). Discharge of solubilized and Dectin-1-reactive $\beta$-glucan from macrophage cells phagocytizing insoluble $\beta$-glucan particles: involvement of reactive oxygen species (ROS)-driven degradation. Biochem. Biophys. Res. Commun. 421(2): 329-334.

Hobbs, C. (2002). Medicinal Mushrooms: An Exploration of Tradition, Healing, \& Culture (Herbs and Health Series). Botanica Press, p. 251

Hong, F., Yan, J., Baran, J.T., Allendorf, D.J., Hansen, R.D., Ostroff, G.R., Xing, P.X., Cheung, N.-K.V., and Ross, G.D. (2004). Mechanism by Which Orally Administered $\beta-1,3-$ Glucans Enhance the Tumoricidal Activity of Antitumor Monoclonal Antibodies in Murine Tumor Models. J. Immunol. 173(2): 797-806.

Huang, C., Wang, Y., Li, X., Ren, L., Zhao, J., Hu, Y., Zhang, L., Fan, G., Xu, J., Gu, X., Cheng, Z., Yu, T., Xia, J., Wei, Y., Wu, W., Xie, X., Yin, W., Li, H., Liu, M., Xiao, Y., Gao, H., Guo, L., Xie, J., Wang, G., Jiang, R., Gao, Z., Jin, Q., Wang, J., and Cao, B. (2020). Clinical features of patients infected with 2019 novel coronavirus in Wuhan, China. Lancet 395: 497-506.

Ishibashi, K., Miura, N.N., Adachi, Y., Ohno, N., and Yadomae, T. (2001). Relationship between solubility of grifolan, a fungal 1,3- $\beta$-D-glucan and production of tumor necrosis factor by macrophages in vitro. Biosci. Biotechnol. Biochem. 65: 1993-2000.

Ishikawa, H., Fukui, T., Ino, S., Sasaki, H., Awano, N., Kohda, C., and Tanaka, K. (2016). Influenza virus infection causes neutrophil dysfunction through reduced G-CSF production and an increased risk of secondary bacteria infection in the lung. Virology 499: 23-29.

Jesenak, M., Majtan, J., Rennerova, Z., Kyselovic, J., Banovcin, P., and Hrubisko, M. (2013). Immunomodulatory effect of pleuran ( $\beta$-glucan from pleurotus ostreatus) in children with recurrent respiratory tract infections. Int. Immunopharmacol. 15: 395-399.

Jung, K., Ha, Y., Ha, S.K., Han, D.U., Kim, D.W., Moon, W.K., and Chae, C. 
(2004). Antiviral effect of saccharomyces cerevisiae $\beta$-glucan to swine influenza virus by increased production of interferon- $\gamma$ and nitric oxide. J. Vet. Med. B 51: 72-76.

Kalafati, L., Kourtzelis, I., Schulte-Schrepping, J., Li, X., Hatzioannou, A., Grinenko, T., Hagag, E., Sinha, A., Has, C., Dietz, S., de Jesus Domingues, A.M., Nati, M., Sormendi, S., Neuwirth, A., Chatzigeorgiou, A., Ziogas, A., Lesche, M., Dahl, A., Henry, I., Subramanian, P., Wielockx, B., Murray, P., Mirtschink, P., Chung, K.-J., Schultze, J.L., Netea, M.G., Hajishengallis, G., Verginis, P., Mitroulis, I., and Chavakis, T. (2020). Innate Immune Training of Granulopoieses Promotes Antitumor Activity. Cell 183(3): 771-785.

Kaneda, M.M., Messer, K.S., Ralainirina, N., Li, H., Leem, C.J., Gorjestani, S., Woo, G., Nguyen, A.V., Figueiredo, C.C., Foubert, P., Schmid, M.C., Pink, M., Winkler, D.G., Rausch, M., Palombella, V.J., Kutok, J., McGovern, K., Frazer, K.A., Wu, X., Karin, M., Sasik, R., Cohen, E.E.W., and Varner, J.A. (2016). PI3KY is a molecular switch that controls immune suppression. Nature 539: 437-442.

Kankkunen, P., Teirilä, L., Rintahaka, J., Alenius, H., Wolff, H., and Matikainen, S. (2010). (1,3)- $\beta$-Glucans Activate Both Dectin-1 and NLRP3 Inflammasome in Human Macrophages. J. Immunol. 184(11): 63356342.

Kim, H.S., Hong, J.T., Kim, Y., and Han, S.-B. (2011). Stimulatory effect of $\beta$-glucans on immune cells. Immune. Netw. 11: 191-195.

Kitamura, S., Hori, T., Kurita, K., Takeo, K., Hara, C., Itoh, W., Tabata, K., Elgsaeter, A., and Stokke, B.T. (1994). An antitumor, branched ( $1 \rightarrow 3)-\beta-D$ glucan from a water extract of fruiting bodies of Cryptoporus volvatus. Carbohydr Res. 263: 111-121.

Krahenbuhl, J.L., Sharma, S.D., Ferraresi, R.W., and Remington, J.S. (1981). Effects of muramyl dipeptide treatment on resistance to infection with toxoplasma gondii in mice. Infect. Immun. 31: 716-22.

Legentil, L., Paris, F., Ballet, C., Trouvelot, S., Daire, X., Vetvicka, V., Ferrières, V. (2015). Molecular Interactions of $\beta-(1 \rightarrow 3)$-Glucans with Their Receptors. Molecules 20: 9745-9766.

Leonhardt, J., Große, S., Marx, C., Siwczak, F., Stengel, S., Bruns, T., Bauer, R., Kiehntopf, M., Williams, D.L., Wang, Z.Q., Mosig, A.S., Weis, S. Bauer, M., and Heller, R. (2018). Candida albicans $\beta$-glucan differentiates human monocytes into a specific subset of macrophages. Front. Immunol. 30(9): 2818

Liang, J., Melican, D., Cafro, L., Palace, G., Fisette, L., Armstrong, R., and Patchen, M.L. (1998). Enhanced clearance of a multiple antibiotic resistant Staphylococcus aureus in rats treated with PGG-glucan is associated with increased leukocyte counts and increased neutrophil oxidative burst activity. Int. J. Immunopharmacol. 20: 595-614.

Lopes, J.L., Quinteiro, V.S.T., Wouk, J., Darido, M.L., Dekker, R.F.H., BarbosaDekker, A.M., Vetvicka, V., Cunha, M.A.A., Faccin-Galhardi, L.C., and Orsato, A. (2021). Sulfonated and Carboxymethylated $\beta$-Glucan Derivatives with Inhibitory Activity against Herpes and Dengue Viruses. Int. J. Mol. Sci. 22: 11013

Majtan, J. (2013). Pleuran ( $\beta$-Glucan from Pleurotus ostreatus): an effective nutritional supplement against upper respiratory tract infections? Med. Sport Sci. 59: 57-61.

Medina-Gali, R., Ortega-Villaizan, M.D.M., Mercado, L., Novoa, B., Coll, J., and Perez, L. (2018). B-glucan enhances the response to SVCV infection in zebrafish. Dev. Comp. Immunol. 84: 307-314.

Medzhitov, R. (2013). Pattern recognition theory and the launch of modern innate immunity. J. Immunol. 191(1): 4473-4477.

Mezu-Ndubuisi, O.J., and Maheshwari, A. (2021). The role of integrins in inflammation and angiogenesis. Pediatr. Res. 89(7): 1619-1626.

Minihane, A.M., Vinoy, S., Russell, W.R., and Baka, A. (2015). Low-grade inflammation, diet composition and health: current research evidence and its translation. Br. J. Nutr. 114(7): 999-1012.

Mitroulis, I., Ruppova, K., Wang, B., Chen, L.S., Grzybek, M., Grinenko, T., Eugster, A., Troullinaki, M., Palladini, A., Kourtzelis, I., Chatzigeorgiou, A., Schlitzer, A., Beyer, M., Joosten, L.A.B., Isermann, B., Lesche, M., Petzold, A., Simons, K., Henry, I., Dahl, A., Schultze, J.L., Wielockx B., Zamboni, N., Mirtschink, P., Coskun, Ü., Hajishengallis, G., Netea, M.G., and Chavakis, T. (2018). Modulation of Myelopoiesis Progenitors Is an Integral Component of Trained Immunity. Cell 172: 147-61.

Moerings, B.G.J., de Graaff, P., Furber, M., Witkamp, R.F., Debets, R., Mes, J.J., van Bergenhenegouwen, J., and Govers, C. (2021). Continuous Exposure to Non-Soluble $\beta$-Glucans Induces Trained Immunity in M-CSF-
Differentiated Macrophages. Front. Immunol. 12: 672796.

Municio, C., Alvarez, Y., Montero, O., Hugo, E., Rodríguez, M., Domingo, E. Alonso, S., Fernández, N., and Crespo, M.S. (2013). The response of human macrophages to $\beta$-glucans depends on the inflammatory $\mathrm{mi}$ lieu. PLoS One 8(4): e62016.

Murphy, E.A., Davis, J.M., Brown, A.S., Carmichael, M.D., Ghaffar, A., and Mayer, E.P. (2012). Effects of oat $\beta$-glucan on the macrophage cytokine response to herpes simplex virus 1 infection in vitro. J. Interferon. Cytokine Res. 32: 362-7.

Netea, M.G., Dominguez-Andres, J., Barreiro, L.B., Chavakis, T., Divangahi, M., Fuchs, E., Joosten, L.A.B., van der Meer, J.W.M., Mhlanga, M.M. Mulder, W.J.M., Riksen, N.P., Schlitzer, A., Schultze, J.L., Stabell Benn C., Sun, J.C., Xavier, R.J., and Latz, E. (2020a). Defining trained immunity and its role in health and disease. Nat. Rev. Immunol. 20: 375-388.

Netea, M.G., Giamarellos-Bourboulis, E.J., Domínguez-Andrés, J., Curtis, N., Crevel, R., van de Veerdonk, F.L., and Bonten, M. (2020b). Trained Immunity: a Tool for Reducing Susceptibility to and the Severity of SARSCoV-2 Infection. Cell 181(5): 969-977.

O’Brien, X.M., Heflin, K.E., Lavigne, L.M., Yu, K., Kim, M., Salomon, A.R., and Reichner, J.S. (2012). Lectin Site Ligation of CR3 Induces Conformational Changes and Signaling. J. Biol Chem. 287(5): 3337-3348.

Ogbole, O.O., Segun, P.A., Akinleye, T., and Fasinu, P.S. (2018). Antiprotozoal, antiviral and cytotoxic properties of the Nigerian Mushroom Hypoxylon fuscum Pers. Fr. (Xylariaceae). Pharm. Sci. 56(4): 43-56.

Ohno, N., Uchiyama, M., Tsuzuki, A., Tokunaka, K., Miura, N.N., Adachi, Y., Aizawa, M.W., Tamura, H., Tanaka, S., and Yadomae, T. (1999). Solubilization of yeast cell-wall $\beta$-(1-3)-D-glucans by sodium hypochlorite oxidation and dimethyl sulfoxide extraction. Carbohydr Res 316 161-172.

Ohno, N., Kurachi, K., and Yadomae, T. (1987). Antitumor activity of a highly branched (1-3)- $\beta$-D-glucan, SSG, obtained from Sclerotinia sclerotiorum IFO 9395. J. Pharmacobiodyn. 10(9): 478-486.

Ooi, V.E.C., and Liu, F. (2000). Immunomodulation and anti-cancer activity of polysaccharide-protein complexes. Curr. Med. Chem. 7(7): 715-729.

Ozment, T.R., Goldman, M.P., Kalbfleisch, J.H., and Williams, D.L. (2012) Soluble Glucan Is Internalized and Trafficked to the Golgi Apparatus in Macrophages via a Clathrin-Mediated, Lipid Raft-Regulated Mechanism. J. Pharmacol. Exp. Ther. 342(3): 808-815.

Pawelec, G. (2018). Age and immunity: What is "immunosenescence". Exp. Gerontol. 105: 4-9.

Petit, J., Embregts, C.W.E., Forlenza, M., and Wiegertjes, G.F. (2019). Evidence of trained immunity in a fish: conserved features in carp mac rophages. J. Immunol. 203: 216-24.

Radzki, W., Ziaja-Sołtys, M., Nowak, J., Rzymowska, J., Topolska, J., Sławińska, A., Michalak-Majewska, M., Zalewska-Korona, M., and Kuczumow, A. (2016). Effect of processing on the content and biological activity of polysaccharides from Pleurotus ostreatus mushroom LWT-Food Science and Technology 66: 27-33.

Reis, F.S., Martins, A., Vasconcelos, M.H., Morales, P., and Ferreira, I.C.F.R. (2017). Functional foods based on extracts or compounds derived from mushrooms. Trends Food Sci. Technol. 66: 48-62.

Ribes, S., Meister, T., Ott, M., Redlich, S., Janova, H., Hanisch, U.K., Nessler, S., and Nau, R. (2014). Intraperitoneal prophylaxis with CpG oligodeoxynucleotides protects neutropenic mice against intracerebral Es cherichia coli K1 infection. J. Neuroinflamm. 11: 14.

Rice, P.J., Adams, E.L., Ozment-Skelton, T., Gonzalez, A.J., Goldman, M.P., Lockhart, B.E., Barker, L.A., Breuel, K.F., Deponti, W.K., Kalbfleisch, J.H., Ensley, H.E., Brown, G.D., Gordon, S., and Williams, D.L. (2005). Oral delivery and gastrointestinal absorption of soluble glucans stimulate increased resistance to infectious challenge. J. Pharmacol. Exp. Ther. 314(3): 1079-1086.

Roy, D., Ansari, S., Chatterjee, A., Luganini, A., Ghosh, S.K., and Chakraborty, N. (2020). In Vitro Search for Antiviral Activity against Human Cytomegalovirus from Medicinal Mushrooms Pleurotus sp. and Lentinus sp. J. Antivir. Antiretrovir. 12(3): 201.

Saeed, S., Quintin, J., Kerstens, H.H., Rao, N.A., Aghajanirefah, A., Matarese F., Cheng, S.-C., Ratter, J., Berentsen, K., van der Ent, M.A., Sharifi, N., Janssen-Megens, E.M., Huurne, M.T., Mandoli, A., van Schaik, T., Ng, A., Burden, F., Downes, K., Frontini, M., Kumar, V., Giamarellos-Bourboulis, E.J., Ouwehand, W.H., van der Meer, J.W.M., Joosten, L.A.B., Wijmenga, C., Martens, J.H.A., Xavier, R.J., Logie, C., Netea, M.G., and 
Stunnenberg, H.G. (2014). Epigenetic programming of monocyte-tomacrophage differentiation and trained innate immunity. Science 345(6204): 1251086.

Sahasrabudhe, N.M., Dokter-Fokkens, J., and de Vos, P. (2016). Particulate $\beta$-glucans synergistically activate TLR4 and Dectin-1 in human dendritic cells. Mol. Nutr. Food. Res. 60(11): 2514-2522.

Sakurai, T., Hashimoto, K., Suzuki, I., Ohno, N., Oikawa, S., Masuda, A., and Yadomae, T. (1992). Enhancement of murine alveolar macrophage functions by orally administered $\beta$-glucan. Int. J. Immunopharmacol. 14: 821-830.

Sandvik, A., Wang, Y.Y., Morton, H.C., Aasen, A.O., Wang, J.E., and Johansen, F.E. (2007). Oral and systemic administration of $\beta$-glucan protects against lipopolysaccharide-induced shock and organ injury in rats. Clin. Exp. Immunol. 148: 168-177.

Sarangi, I., Ghosh, D., Bhutia, S.K., Mallick, S.K., and Maiti, T.K. (2006). Antitumor and immunomodulating effects of Pleurotus ostreatus mycelia-derived proteoglycans. Int. Immunopharmacol. 6(8): 1287-1297.

Sawai, M., Adachi, Y., Kanai, M., Matsui, S., and Yadomae, T. (2002). Extraction of conformationally stable (1-6)-branched (1-3)- $\beta$-D-glucans from premixed edible mushroom powders by cold alkaline solution. Int. J. Med. Mushr. 4: 197-205.

Schmid, M.C., Khan, S.Q., Kaneda, M.M., Pathria, P., Shepard, R., Louis, T.L., Anand, S., Woo, G., Leem, C., Faridi, M.H., Geraghty, T., Rajagopalan, A., Gupta, S., Ahmed, M., Vazquez-Padron, R.I., Cheresh, D.A., Gupta, V., and Varner, J.A. (2018). Integrin CD11b activation drives anti-tumor innate immunity. Nat. Commun. 9: 5379.

Sekheri, M., Othman, A., and Filep, J.G. (2021). $\beta 2$ Integrin Regulation of Neutrophil Functional Plasticity and Fate in the Resolution of Inflammation Front. Immunol. 12: 660760.

Sica, A., and Mantovani, A. (2012). Macrophage plasticity and polarization: in vivo veritas. J. Clin. Invest. 122: 787-795.

Soares, E., Groothuismink, Z.M.A., Boonstra, A., and Borges, O. (2019). Glucan Particles Are a Powerful Adjuvant for the HBsAg, Favoring Antiviral Immunity. Mol. Pharmaceutics 16: 5.

Sullivan, R., Smith, J.E., and Rowan, N.J. (2006). Medicinal mushrooms and cancer therapy: translating a traditional practice into Western medicine. Perspect. Biol. Med. 49(2): 159-170.

Swidergall, M., Solis, N.V., Lionakis, M.S., and Filler, S.G. (2018). EphA2 is an epithelial cell pattern recognition receptor for fungal $\beta$-glucans. Nat. Microbiol. 3: 53-61.

Tanaka, A., Nishimura, M., Sato, Y., Sato, H., and Nishihira, J. (2016). Enhancement of the Th1-phenotype immune system by the intake of Oyster mushroom (Tamogitake) extract in a double-blind, placebo- controlled study. J. Tradit. Complement. Med. 6(4): 424-430.

Urbancikova, I., Hudackova, D., Majtan, J., Rennerova, Z., Banovcin, P., and Jesenak, M. (2020). Efficacy of Pleuran ( $\beta$-Glucan from Pleurotus ostreatus) in the Management of Herpes Simplex Virus Type 1 Infection. Evid. Based Complement Alternat. Med. 2020: 8562309.

Usui, S., Tomono, Y., Sakai, M., Kiho, T., and Ukai, S. (1995). Preparation and antitumor activities of beta-(1-6) branched $(1 \rightarrow 3)-\beta$-D-glucan derivatives. Biol. Pharm. Bull. 18: 1630-1636.

van der Meer, J.W., Joosten, L.A., Riksen, N., and Netea, M.G. (2015). Trained immunity: a smart way to enhance innate immune defence. Mol. Immunol. 68: 404

van't Wout, J.W., Poell, R., and van Furth, R. (1992). The role of BCG/PPDactivated macrophages in resistance against systemic candidiasis in mice. Scand. J. Immunol. 36: 713-719.

Vandanmagsar, B., Youm, Y.H., Ravussin, A., Galgani, J.E., Stadler, K., Mynatt, R.L., Ravussin, E., Stephens, J.M., and Dixit, V.D. (2011). The NLRP3 inflammasome instigates obesity-induced inflammation and insulin resistance. Nat. Med. 17(2): 179-188.

Vetvicka, V., and Vetvickova, J. (2015). Glucan supplementation enhances the immune response against an influenza challenge in mice. Ann. Transl. Med. 3: 22.

Vetvicka, V., Vannucci, L., Sima, P., and Richter, J. (2019). Beta Glucan: Supplement or Drug? From Laboratory to Clinical Trials. Molecules 24: 1251.

Vetvicka, V., Vashishta, A., Saraswat-Ohri, S., and Vetvickova, J. (2008). Immunological effects of yeast-and mushroom-derived $\beta$-glucans. J. Med. Food. 11(4): 615-622.

Wasser, S. (2002). Medicinal mushrooms as a source of antitumor and immunomodulating polysaccharides. Appl. Microbiol. Biotechnol. 60(3): 258-274.

Willard, T. (1990). The Reishi Mushroom: Herb of Spiritual Potency and Medical Wonder. Sylvan Press, Seattle, p. 167.

Zhang, B., Chassaing, B., Shi, Z., Uchiyama, R., Zhang, Z., Denning, T.L., Crawford, S.E., Pruijssers, A.J., Iskarpatyoti, J.A., Estes, M.K., Dermody, T.S., Ouyang, W., Williams, I.R., Vijay-Kumar, M., and Gewirtz, A.T. (2014). Viral infection. Prevention and cure of rotavirus infection via TLR5/NLRC4-mediated production of IL-22 and IL-18. Science 346: 861-865.

Zhang, P., Zhang, L., and Cheng, S. (1999). Chemical structure and molecular weights of $\alpha$-(1,3)-D-glucan from Lentinus edodes. Biosci. Biotechnol. Biochem. 63: 1197-1202.

Zheng, M.X., Zhu, Y.J., Liu, B., Gao, X.F., and Chen, Z. (2018). Research progress on $\beta$-glucan and its application on food industry. J. Food Saf. Food Qual. 19(16): 4333-4342. 